\title{
MULTIMODAL TRANSPORT IN THE ADRIATIC - IONIAN REGION: A TRANSNATIONAL APPROACH AND STRATEGY FOR IMPROVEMENT DURING THE COVID-19 PANDEMIC ERA
}

\author{
Paolo Dileno $^{1}$, Marios Miltiadou ${ }^{2}$, Efstathios Bouhouras ${ }^{3}$, Christos Taxiltaris ${ }^{4}$, \\ Georgios Mintsis $^{5}$, Socrates Basbas ${ }^{6}$, Irene Sabbadini ${ }^{7}$, Giuseppe Luppino ${ }^{8}$, Roberto \\ Richter ${ }^{9}$, Nebojsa Jevtic ${ }^{10}$ \\ ${ }^{1}$ Central European Initiative (CEI), Italy \\ $2,3,4,5,6$ Laboratory of Transportation Planning, Transportation Engineering \& Highway Engineering, School of \\ Rural and Surveying Engineering, Aristotle University of Thessaloniki (AUTH), Thessaloniki, Greece \\ 7,8 Institute for Transport and Logistics (ITL), Italy \\ ${ }^{9}$ Port of Koper (LK - Luka Koper, port and logistic system, public limited company), Slovenia \\ ${ }^{10}$ Chamber of Commerce and Industry (CCIS), Serbia
}

Received 8 February 2021; accepted 15 March 2021

\begin{abstract}
One of the main objectives of the project "Integrating multimodal connections in the Adriatic-Ionian region" (ADRIPASS) is to deal with the commonly recognized lack of efficient maritime - hinterland connections, which are mainly caused by the existence of various bottlenecks at borders. This is achieved by identifying and analysing these - physical and non-physical - bottlenecks along the Trans-European Transport Networks (TEN-T) corridor sections in the Adriatic - Ionian (ADRION) region, with specific attention paid to those corridors that have been indicatively extended to the Western Balkans (WB) region, where the issue of border crossings is quite relevant. The Covid-19 pandemic outbreak affects the entire globe, including Europe, in many and different ways. In the fight against the spread of Covid-19, national governments of the European Union (EU) introduced temporary restrictions to border traffic of various degrees, ranging from border controls to outright closure. In this framework, ADRIPASS took duly into account the experience gained during the period of Covid-19 in the Transnational Strategy for the improvement of multimodal transport and accessibility in the ADRION region, developed as the final output of the project. The current paper presents in a summarized way the activities, results and outputs, including the defined Strategy and specific proposals related to transport facilitation for the period to follow.
\end{abstract}

Keywords: ADRIPASS, border crossings, Western Balkans, Covid-19 pandemic, transnational strategy, Adriatic-Ionian region, multimodal transport.

\section{Introduction}

ADRIPASS, co-funded by European Regional Development Fund and the Instrument for Pre-Accession II funds in the framework of the Interreg ADRION Programme 2014-2020, was implemented in the period January 2018 - December 2020 by a group of eleven (11) partners from Albania, Bosnia and Herzegovina,

${ }^{2}$ Corresponding author: mmiltiadou@auth.gr 
Croatia, Greece, Italy, Montenegro, Serbia and Slovenia. The project was dedicated to identifying the lack of efficient maritime - hinterland connections, mainly caused by the existence of various bottlenecks at border level and to propose solutions and tools for the reduction of these bottlenecks and mitigation of their impact on transport (ADRIPASS Partnership, 2016).
The ADRION Region, as defined by the respective Interreg Programme, covers both the Adriatic and the Ionian Seas and their hinterlands to the west-northwest and to the east-southeast, respectively. This region (Fig. 1) virtually defines the area of ADRIPASS, whilst it perfectly matches with the EU Strategy for the Adriatic - Ionian Region (EUSAIR) area.

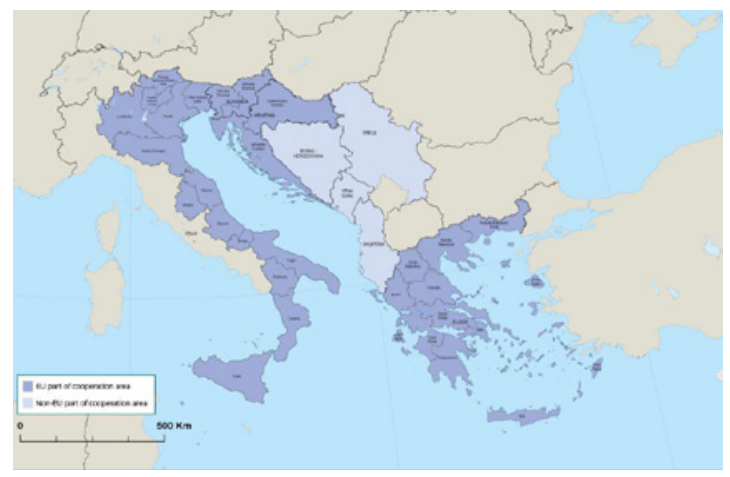

Fig. 1.

ADRION and EUSAIR Region

Source: (Adriatic-Ionian Programme, 2017)

ADRIPASS aimed to contribute to tackling this problem by:

a) Analyzing physical and non-physical bottlenecks along the TEN-T corridors sections of the ADRION region, with specific focus on those recently extended to the WB, where most Border Crossing Points (BCPs) are located;

b) By testing specific Information and Communication Technology (ICT) solutions for streamlining freight transport in ADRION ports, setting standards which may be replicated through Electronic Data Interchange (EDI) interfaces at BCPs; and c) Designing a transnational strategy for the enhancement of multimodal transport in the Adriatic Ionian region.

Thus, it is anticipated that ADRION region will benefit from the results of the ADRIPASS activities thanks to the replicability of concrete project tools as the transnational Action Plan for transport facilitation and the ICT Action Plan for improving multimodal transport in the region. Then, the establishment of an enduring multilevel and multidisciplinary transnational cooperation network, simultaneously and innovatively combining a 
bottom-up and top-down approach at BCPs, would guarantee an important impact on the region.

Through the ADRIPASS results, and in particular through the Strategy for the enhancement of multimodal transport efficiency and competitiveness, the planning capacities of transport stakeholders (ports, logistic operators, freight forwarders, railway companies) and national and European policymakers (Ministries of Transport, European Commission, Core TEN-T Corridors coordinators) is expected to be significantly improved, since all of them are facing the same challenges concerning the multimodal transport accessibility and network efficiency on the Core TEN-T Corridors sections in the ADRION and particularly the connections from the ports to the hinterland.

\section{Methodological Approach}

The identification and analysis of the existing obstacles along the main TEN-T Corridors sections in the ADRION region was the cornerstone of the project. The methodological approach comprised a joint data collection methodology (ADRIPASS Partnership, 2018a), the performance of desktop, questionnaire-based surveys, on-site visits, meetings with stakeholders (including the transport industry, managing authorities of BCPs, ports, Inland Waterway - IWW - ports) and desktop research.

The project's workflow diagram is illustrated in Fig. 2.

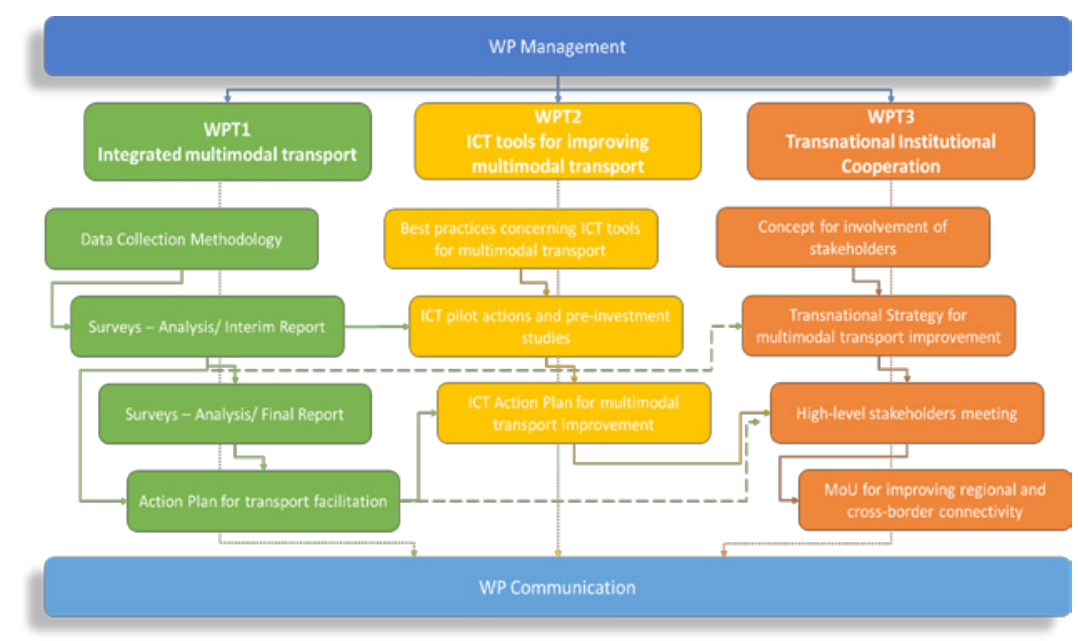

Fig. 2.

ADRIPASS Workflow Diagram

Source: (ADRIPASS Partnership, 2018a) 
The data collection process concerned thirty (30) Road and twenty-one (21) Rail BCPs (Fig. 3), fourteen (14) maritime ports and twenty-eight (28) Logistic Facilities located in ten (10) countries
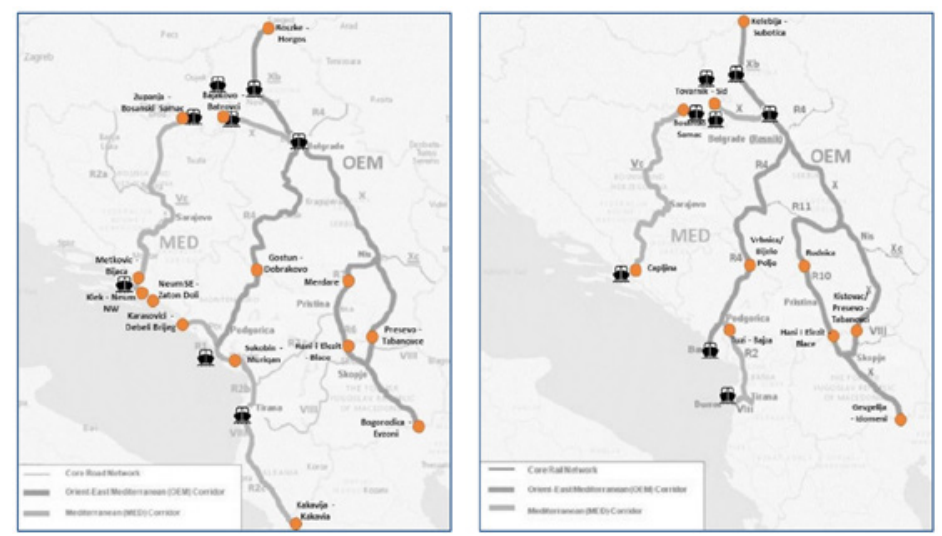

\section{Fig. 3.}

Map of Road (Left) and Rail (Right) BCPs and Ports of Interest along the Trans-European Core Network Corridors Extension in WB

Source: (own elaboration on map background from Mott MacDonald - IPF Consortium, 2016)

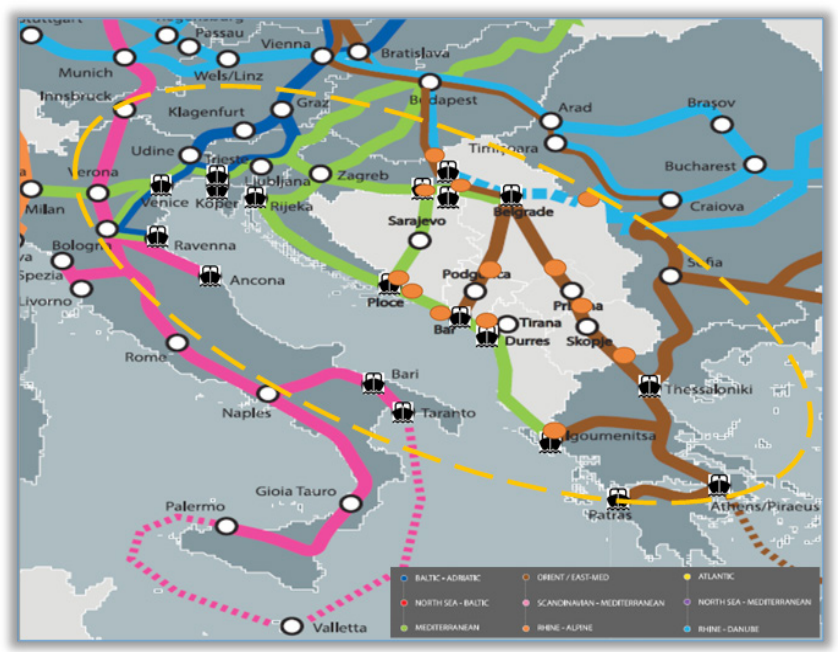

Fig. 4.

Map of Core TEN-T Corridors in the ADRION Region

Source: (own elaboration on map background from European Commission, 2015) 
Despite many difficulties in the data collection process, mainly owed to administrative issues and unwillingness in few cases - of different types of transport nodes' managing authorities to participate to the survey, data was collected for $94 \%$ of the Road BCPs, for all the Rail BCPs, $87 \%$ of the maritime ports and $71 \%$ of the Logistic Facilities.

The Corridors Analysis comprised an integrated presentation of the current situation and a Multi-Criteria Analysis (MCA) developed and customized to the needs of the project and based on the previous relevant research in the region (Miltiadou et al., 2014, 2016, 2017; ACROSSEE Partnership, 2013, 2014a, $2014 b$ ), focused on promoting soft measures (through the implementation of ICT tools and applications) to contribute to the elimination of non-physical barriers for freight transport in the ADRION area.

This analysis served as a feeder to the Transnational Action Plan for transport facilitation, as well to the other main project's activities and outputs, such as the definition and implementation of ICT pilot actions at selected ports, formulation of an ICT Action Plan, and elaboration of a Transnational Strategy for improving multimodal transport in the ADRION region. The latter concluded the outputs of the project, based on a combination of bottom-up (from the research and the implementation of specific pilot actions) and top-down (direct communication with the project's Associated Partners, e.g., Ministries, international organizations, as policy makers) approaches. These outputs of the project and their main results are briefly presented in the following chapter.

\section{Action Plans}

\subsection{Transnational Action Plan for Transport Facilitation}

The results of the MCA together with a review of the relevant strategic studies and plans complementary with the Action Plan in terms of geographic scope and technical content brought to the identification of measures proposed in relation to the identified problems, clustered per type of transport node.

These measures are based on the following eight (8) macro-categories defining the identified barriers/ problems (ADRIPASS Partnership, 2018b):

- Deficiency of existing ICT technologies/ solutions for the digitalization of processes and system interoperability: Identified 4 times at maritime ports, 14 times at Road BCPs, 13 times at Rail BCPs and 1 time at a Logistic Facility (32 in total);

- Inadequate staff number and competences; lengthy and paperbased procedures, long waiting times of intermodal and border crossing procedures: Identified 8 times at maritime ports, 48 times at Road BCPs, 28 times at Rail BCPs, 5 times at Inland Waterway facilities and 3 times at Logistic Facilities (92 in total);

- Lack or deficiency of the existing telematic applications for traffic management: Identified in two cases (1 Road BCP and 1 Rail BCP);

- Lack or poor conditions of the basic utilities, such as water, light, telephone and internet: Identified 18 times at Road BCPs and 16 times at Rail BCPs (34 in total); 
- $\quad$ Lack of adequate equipment affecting the efficiency and effectiveness of processes at BCPs and transport nodes. This includes machinery, such as cranes weighbridges, X-ray scanners, etc.: Identified 37 times at Road BCPs, 7 times at Rail BCPs, 1 time at Inland Waterway Facility and 3 times at Logistic Facilities (48 in total);

- Deficiency in the last-mile and hinterland transport interconnecting system (both inside and outside the node area): Identified 20 times at maritime ports and 7 times at Logistic Facilities (27 in total);

- Need for major infrastructure works and/ or minor investments to remove physical and technical barriers, affecting operations and capacity of the infrastructure: Identified 12 times at maritime ports, 21 times at Road BCPs, 10 times at Rail BCPs and 2 times at Inland Waterway Facilities (45 in total);

- Complete lack of alternative clean fuels supply facilities.

The proposed measures/ solutions were then clustered in the following eight (8) categories:

- Improvement/ upgrade of the existing ICT infrastructure to foster transport digitalization, the interoperability of communication and data sharing systems: Proposed for 50 cases at maritime ports, in 14 cases at Road BCPs, in 2 cases at Rail BCPs and in 5 cases at Logistic Facilities (71 in total);

- Hiring of additional/ specialized personnel and provision of training courses to increase the quality of the working staff; implementation of ICT solutions to solve Operational and Administrative problems: Proposed to be applied at in 2 cases at maritime ports, in 2 cases at Road BCPs and in 3 cases at Rail BCPs (7 in total);

- Deployment or upgrade of telematic applications for traffic management to the EU standards: Proposed to be applied in one case at a maritime port and in two cases of Rail BCPs (3 in total);

- Provision of basic utilities (internet, drinkable water, toilettes, etc.): Proposed to be applied at one Inland Waterway Facility;

- Purchase and installation of equipment for the improvement of efficiency and effectiveness of processes at BCPs and transport nodes: Proposed to be applied in 5 cases at maritime ports, in 2 cases at Road BCPs, in 2 cases at Inland Waterway Facilities and in 2 cases at Logistic Facilities (11 in total);

- Infrastructure improvement or expansion of the road and rail lastmile connections within and outside the node areas: Proposed to be applied in 18 cases at maritime ports and in 5 cases at Logistic Facilities (23 in total);

- New construction or modernization of existing infrastructure aiming to remove physical and technical barriers or to increase the actual capacity: Proposed to be applied in 30 cases at maritime ports, in 9 cases at Road BCPs, in 2 cases at Rail BCPs, in 7 cases at Inland Waterway Facilities and in 3 cases at Logistic Facilities (51 in total);

- Realization of alternative clean fuels supply facilities: Proposed to be applied at 2 maritime ports ( 2 in total).

Clearly, the different types of transport nodes analyzed could face one or more of the identified barriers/ problems and therefore one or more of the proposed 
measures/ solutions could be applied to any of the nodes. The Transnational Action Plan presented thoroughly the identified measures for transport facilitation, their applicability, the Corridors concerned, the involved stakeholders, the time horizon for the implementation and finally a prioritization of the measures.

\subsection{ICT Action Plan}

As abovementioned, besides - and based on - the analysis of the current situation and the identification problems and respective measures, the project identified and tested solutions to share them at regional level in an effort to adopt common methodologies and strategies for the new type of challenges in which the logistic operators were catapulted during the last decade (ADRIPASS Partnership, 2020a). To this end, four pilot actions were identified, designed and implemented at ports:

- For the Port of Koper (Slovenia), organizational aspects and methodologies were assessed, and the implemented interventions comprised upgrades of ICT equipment and substitution of existing tools with the proper solutions for marketing and operations (warehousing, ordering, invoicing) and specialized container terminal operating and management system, in order to follow the trends and to accept the growing volumes of inbound and outbound cargo.

- For the Port of Ploce (Croatia), the assessment concluded to the need for upgrade of the existing technology, by an upgrade of all Port's Community System application modules for streamlining freight flows by improving communication with port supply chain stakeholders.

- For the Port of Bar (Montenegro), the pilot action comprised upgrade of the existing Port Community System to a newer version, with upgrades of the control center, of the customs and trucks modules, of the mobile application for PSC users and of the User Interface.

- For the Port of Igoumenitsa (Greece), two activities were identified and implemented by the Regional Unit of Thesprotia: a) development of a web platform for collection of data from the Port Authority (involved to the project as Associate Partner) and present it to the public in a comprehensive and userfriendly way by using Analytics and Business Intelligence tools for flows forecasting; and b) development of a mobile application (for all operative systems) which offers the passengers and visitors a tour to the port's facilities by using Augmented Reality technology.

- Finally, a pre-investment study for establishment of Port Community System in the Port of Durres has been elaborated.

The ICT Action Plan concludes that it can be commonly accepted that there is a general lack of technology and technological processes. All over the world the automatization is something that is becoming real and daily. All the equipment and innovations adopted in major logistic nodes are bringing solutions for processes, data storage and sharing, communication systems and local software dimensions. The same development is expected in the ADRION region for which the tools and improvements developed through the pilot activities are expected to be useful also for other realities in the same area, where the linked logistic actors will 
have the possibility to join the databases and functionalities proposed by the partners that developed these solutions (ADRIPASS Partnership, 2020a).
The steps to be followed for the development of solutions to a larger scale in the ADRION region as presented in the ICT Action Plan are presented in Fig. 5.

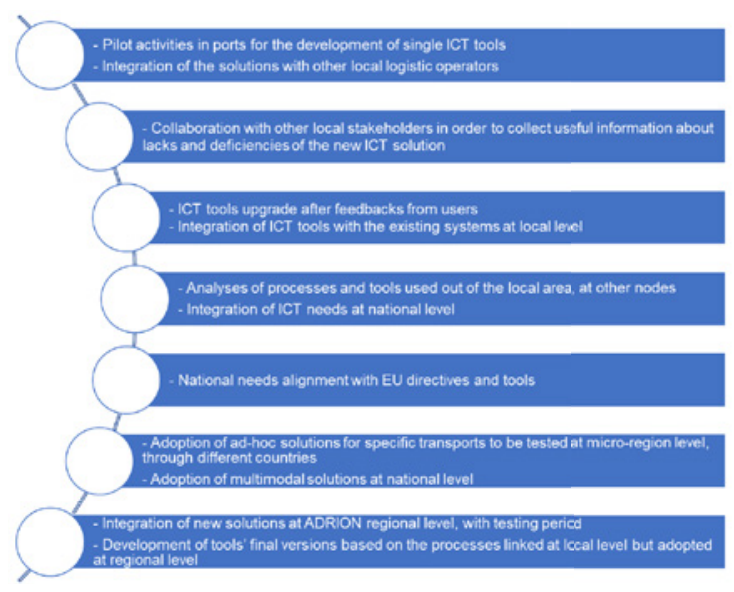

Fig. 5.

Steps for the Replication of ICT Solutions at Regional Level

Source: own elaboration

\section{Transnational Strategy for Improvement of Multimodal Transport and Accessibility}

\subsection{Mission, Vision, Objectives and Measures}

The Transnational Strategy for the Improvement of Multimodal Transport and Accessibility in the ADRION region took into consideration all relevant and related international territorial and political subjects, organizations and initiatives, creating thus a multilevel framework in a complex environment for transport development and regional connectivity.

Several documents were analyzed, and the vision set is for the ADRION region to become a region with high quality multimodal transport and logistics services. The mission of the Strategy is to ensure faster, safer, more efficient and more effective multimodal transport and logistic services and competitive cargo operation in the ADRION region. Specifically, it is to contribute to the improvement of multimodal transport links in the ADRION region by strengthening the efficiency of stakeholders (port authorities, terminal/ logistic operators, freight forwarders) and providing guidelines to policy makers at national level (ADRION national Ministries of Transport) to implement measures to multimodal transport facilitation on the TEN-T Corridors in the ADRION region (ADRIPASS Partnership, 2020b).

Moreover, the Strategy envisages to increase the capacity of ADRION transport policy makers at European level (European Commission - 
DG MOVE, DG REGIO and DG NEAR European Transport Corridor Coordinators, Transport Community) to plan transport facilitation measures in ADRION region, with a special focus on the recently extended TEN-T Corridors to the Western Balkans.

In order develop multimodal operations across all modes of transport in the multimodal transport chain, the Strategy proposes:

- Simplification of the administrative procedures at Border Crossing Points;

- Improve cooperation among all participants in the multimodal transport chain.

It is acknowledged that it is necessary to improve ICT technologies for the digitalization of processes and system operability in the main multimodal nodes and, for this to be achieved, the following measures are proposed:

- Development of intelligent transport systems in the main multimodal nodes;

- Improvement of staff knowledge and procurement of adequate equipment for staff and users in the main multimodal nodes.

The Strategy also identified the necessity of stimulative measures for promoting multimodal transport as environmentally friendly transport solution.

Finally, several horizontal measures are proposed, able to contribute to the multimodal facilitation in the ADRION region, which concern:

- Legislative, regulatory and administrative issues;

- Technical standards;

- Human resources, social dialogue and strengthening institutional capacities.

\subsection{Challenges due to Covid-19 Outbreak}

In March 2020, few months before the project completion, the Covid-19 outbreak made the EU governments to introduce temporary restrictions to border traffic, ranging from border controls to outright closure. In several cases this had a severe impact on freight traffic as border controls led to tens of kilometers of traffic congestion, such as between Poland and Germany. Practical advice on how the Commission's Guidelines for border management should be implemented was issued. To ensure that EU-wide supply chain would continue to operate, Member States were asked to designate, without delay all the relevant internal border - crossing point on the trans-European transport network (TEN-T) as 'green lane' border crossings. The green lane border crossings should be open to all freight vehicles whatever goods are carrying and it was emphasized that crossing the border, including all checks and health screening, should not take more than 15 minutes.

The WB countries as all countries in the world had, in the meantime, also taken some restrictive - and often uncoordinated measures for travel and transport of goods. These, combined with those taken by the EU Member States, caused an increase of the congestion at some border-crossings, with long queues and long delays to pass the border, with potentially adverse effect on the sanitary situation, but also on the supply of essential goods.

The crisis also resulted in social impacts, where professionals including truck drivers, customs and border officers often got stuck for days in a line at border clearance posts and exposed to possible Covid-19 contagion, 
given the - often precarious - infrastructure and sanitary situation at many land border crossings across the region.

However, despite the sanitary emergency, the flow of goods and, above all, of goods of primary needs (food, medicines and medical equipment, animal feed) shouldn't be interrupted. As this sanitary emergency will last for a certain time, beyond the consequences in terms of loss of human lives, the overall economy of the continent (as well as worldwide) and its trade component might be heavily affected. WB governments have expressed their fear that there could be a disruption of cargo traffic which could lead to shortage of essential goods affecting the life of millions of citizens in the region.

As per the Commission's instructions, checks and screenings at border crossings should be carried out without the drivers having to leave their vehicles, and drivers themselves should undergo only minimal checks. Drivers of freight vehicles should not be asked to produce any document other than their identification and driving license and, if necessary, a letter from the employer. The electronic submission/ display of documents should be accepted. It must be noted that according to the collected data through the ADRIPASS, at 13 out of 28 Road BCPs, the Customs Declarations can be electronically submitted (partially or fully). Furthermore, at 5 out of 28 Road BCPs the supporting documents could also be submitted electronically. However, it must be noted that the majority of the Road BCPs did not provide the required data (11 out of 28 regarding the Customs Declarations electronic submission and 15 out of 28 regarding the electronic submission of the supporting documents). In any case, the Commission sought close cooperation with the governments of the WB regarding this issue.

The institutional cooperation of the EU with WB is established through the Transport Community Treaty Permanent Secretariat (TCT). The TCT began to monitor the travel restrictions set up by the different SEE partners, including Member States. In cooperation with the WB authorities, the TCT provided a daily update and particularly regarding the situation at borders.

Following the Commission's guidelines for border management measures to protect health and ensure the availability of goods and essential services (European Commission, 2020a) and the New Practical guidance to ensure continuous flow of goods across EU via green lanes (European Commission, 2020b), the TCT presented a joint proposal with CEFTA (Central European Free Trade Agreement) Secretariat to facilitate transport and trade for essential goods within the WB region (Transport Community Permanent Secretariat \& Central European Free Trade Agreement Secretariat, 2020). Among other proposals, one was the definition of "Green" priority Corridors on which free flow of goods of first necessity should be granted. These comprised the following priority sections:

a) Branch B of Corridor X from Hungarian border to Belgrade, Skopje, Pristina and Greece, and Route 4 from Romanian border to Belgrade, Podgorica and Port of Bar;

b) Corridor V to Banja Luka, Sarajevo and Port of Ploce, Corridor X from Croatian border to Belgrade, Nis and Bulgarian border (Branch C), border of Serbia with Bosnia and Herzegovina to Sarajevo and 
Banja Luka and further to Montenegro and Kosovo*; and

c) Corridor VIII from Port of Durres to Tirana, Skopje and Bulgarian border, Port of Durres to Greece, Route 7 from Albania to Pristina and border with North Macedonia and the link from Albania to Podgorica.
Thanks to the WB regional participants and the TCT efforts, the average waiting times at main border crossing points within the WB region (internal borders) and at borders with EU countries are presented on very frequent basis during the period since the beginning of Covid-19 crisis (example in Fig. 6).

Fig. 6.

Average Waiting Times at EU/WB BCPs during Covid-19 Pandemic (in Minutes) for the Period April 2020 - June 2020

Source: (Transport Community Permanent Secretariat, 2020)

\section{Conclusions}

Multimodality in transport is considered as one of the prime requirements for economic development and growth and for regional convergence and cohesion. It facilitates the movement and interaction of people and the exchange of goods and ideas. All these aspects are of immense importance in the ADRION region. Given its geographical position on the cross-roads of east-west and north-south axes of Europe, the ADRION region constitutes an important transport route for goods and passengers transport as well as energy.
ADRIPASS identifies four basic directions to which measures should be concentrated on towards strengthening of multimodality and links in the ADRION region:

(i) Improvement of connections of basic multimodal hubs with hinterland, both infrastructural, administratively and operationally;

(ii) Use of modern ICT technologies in the main multimodal nodes;

(iii) Promotion of multimodal transport as an environmentally friendly mode of transport;

(iv) Support of constant cooperation and dialogue among transport stakeholders

\footnotetext{
* This designation is without prejudice to positions on status, and is in line with UNSCR 1244 and the ICJ Opinion on the Kosovo Declaration of Independence
} 
and policy makers to improve the overall efficiency of the transport sector in the region.

Constant and persistent effort is required in order to achieve the highest quality of services at BCPs, combined with up-to-date equipment and technologies. ADRIPASS has successfully completed its objectives not only by identifying the non-physical barriers and problems along the supply chain at the WB area, but also by developing and presenting solid measures and tools to overcome them.

Furthermore, it has been concluded that the ongoing pandemic has not been only the source of many problems, but it could also perform as a lesson for the upcoming years. New protocols must be developed with the participation as many as possible stakeholders of the supply chain, aiming to face emergency and in many times unpredictable conditions.

The ADRION region, and the $\mathrm{WB}$ area in particular, could be a field of implementing innovating measures and solutions, promoting the transnational cooperation in benefit of the region as well as ensuring that multimodal freight transport can become sustainable if the collaboration among the system's stakeholders is achieved.

To this end, ADRIPASS has concluded with establishment of a permanent Transnational multi-level and multi-disciplinary Cooperation Network that will work in the years to come towards sustainable transport in the ADRION region and beyond. The work of this network will be based on the EU relevant guidelines, and during this challenging period on those related to the recovery of transport services and connectivity during the Covid-19 era (European Commission, 2020c).

\section{Acknowledgements}

The authors wish to acknowledge the contribution of all the ADRIPASS project partners (Durres Port Authority, Foreign Trade Chamber of Bosnia and Herzegovina, GECT Euregio Sensa Confini r.l., Ploce Port Authority, Port of Bar Holding company and Regional Unit of Thesprotia/ Region of Epirus) and associate partners for the cooperation in the framework of this project that brings important results for further consideration of the improvement of multimodal transport in the region of South East Europe.

\section{References}

ACROSSEE Partnership. 2013. SEE/D/0093/3.3/X. Accessibility improved at border Crossings for the integration of South East Europe. Project, Transnational Cooperation Programme South East Europe. Shared methodology for common standards analysis on border crossing points.

ACROSSEE Partnership. 2014a. SEE/D/0093/3.3/X. Accessibility improved at border Crossings for the integration of South East Europe. Project, Transnational Cooperation Programme South East Europe. Surveys at Border Crossings.

ACROSSEE Partnership. 2014b. SEE/D/0093/3.3/X. Accessibility improved at border Crossings for the integration of South East Europe. Project, Transnational Cooperation Programme South East Europe. Cutting Stops at Border Crossings.

Adriatic-Ionian Programme. 2017. Adriatic-Ionian Programme, INTERREG V-B Transnational 2014-2020. Available from Internet: <http://www.adriatic-ionian. eu/about/the-adriatic-ionian-region $>$.

ADRIPASS Partnership. 2016. Adriatic-Ionian Programme INTERREG V-B Transnational 2014- 
2020/ Programme Priority3/ ADRIPASS project (166), Integrating multimodal connections in the AdriaticIonian region. Application Form.

ADRIPASS Partnership. 2018a. Adriatic-Ionian Programme INTERREG V-B Transnational 20142020/ Programme Priority 3/ ADRIPASS project (166), Integrating multimodal connections in the AdriaticIonian region/ Deliverable T2.1.1. Joint Methodology for the implementation of the WP.

ADRIPASS Partnership. 2018b. Adriatic-Ionian Programme INTERREG V-B Transnational 20142020/ Programme Priority3/ ADRIPASS project (166), Integrating multimodal connections in the Adriatic-Ionian region/ Deliverable T1.2.4. Final Transnational Action Plan for transport facilitation in the Adriatic-Ionian region.

ADRIPASS Partnership. 2020a. Adriatic-Ionian Programme INTERREG V-B Transnational 20142020/ Programme Priority3/ ADRIPASS project (166), Integrating multimodal connections in the AdriaticIonian region/ Deliverable T2.2.6. ICT Action Plan for Improving Multimodal Transport in Adrion Region.

ADRIPASS Partnership. 2020b. Adriatic-Ionian Programme INTERREG V-B transnational 20142020/ Programme Priority3/ ADRIPASS project (166), Integrating multimodal connections in the AdriaticIonian region/ Deliverable T3.2.2. Transnational Strategy for the Improvement of Multimodal Transport and Accessibility in the ADRION Region.

European Commission. 2015. Directorate General European Neighbourhood Policy and Enlargement Negotiations, Connectivity Agenda. Co-Financing of Investment Projects in the Western Balkans in 2015, Vienna Summit.

European Commission. 2020a. C(2020) 1753 final, Communication from the Commission COVID-19 Guidelines for border management measures to protect health and ensure the availability of goods and essential services.
European Commission. 2020b. C(2020) 1897 final, Communication from the Commission on the implementation of the Green Lanes under the Guidelines for border management measures to protect health and ensure the availability of goods and essential services.

European Commission. 2020c. C(2020) 3139 final: Communication from the Commission - COVID-19: Guidelines on the progressive restoration of transport services and connectivity.

Miltiadou, M.; Bouhouras, E.; Taxiltaris, C.; Mintsis, G. 2014. Towards maximization of the added value of strategic infrastructure projects in South East Europe through improvements at Border Crossing Points. In Proceedings of the 3rd International Conference on Road and Rail Infrastructure (CETRA 2014), Department of Transportation Faculty of Civil Engineering, University of Zagreb, 28 - 30 April 2014, Split, Croatia. Edited by Stjepan Lakušić, ISSN 1848-9842, 137-146.

Miltiadou, M.; Bouhouras, E.; Basbas, S.; Mintsis, G.; Taxiltaris, C. 2016. Improving Border Crossings towards the integration of South East Europe into the European Transport Networks. TransportResearch Arena, TRA Marketplace poster session, 18-21 April 2016, Warsaw, Poland.

Miltiadou, M.; Bouhouras, E.; Basbas, S.; Mintsis, G.; Taxiltaris, C. 2017. Analysis of Border Crossings in South East Europe and measures for their improvement. In Transportation Research Procedia, 25: 603-615.

Mott MacDonald - IPF Consortium. 2016. Connectivity Networks Gap Analysis.

Transport Community Permanent Secretariat \& Central European Free Trade Agreement Secretariat. 2020. Joint proposal to facilitate the transport and trade of essential goods within the Western Balkans.

Transport Community Permanent Secretariat. 2020. Available from Internet: <https://www.transportcommunity.org/2020/07/09/monitoring-waitingtime-at-at-western-balkans-eu-member-states-bordersquarterly-assessment-of-the-post-covid-19-trends>. 